\title{
Correction to: Longitudinal Differences in Response to Name Among Infants Developing ASD and Risk for ADHD
}

\author{
Burt Hatch $^{1,3}$ (1) Ana-Maria losif ${ }^{2} \cdot$ Annie Chuang $^{1} \cdot$ Leiana de la Paz $^{1} \cdot$ Sally Ozonoff ${ }^{1} \cdot$ Meghan Miller $^{1}$
}

Published online: 13 July 2020

○) Springer Science+Business Media, LLC, part of Springer Nature 2020

\section{Correction to: \\ Journal of Autism and Developmental Disorders \\ https://doi.org/10.1007/s10803-020-04369-8}

The original version of this article unfortunately contained a consistency mistake in Fig. 1 legend. The legend for Fig. 1 refers to "Non-ADHD/Non-ASD Concerns" instead of "Comparison," which is the wording used in the text/tables, but that these terms are synonymous.

Figure 1 with the correct legend is given below.

The original article can be found online at https://doi.org/10.1007/ s10803-020-04369-8.

Burt Hatch

bhatch@ucdavis.edu

1 Department of Psychiatry \& Behavioral Sciences and MIND Institute, University of California, Davis, Davis, USA

2 Division of Biostatistics, Department of Public Health Sciences, University of California, Davis, Davis, USA

3 MIND Institute, University of California Davis Health System, 2825 50th Street, Sacramento, CA 95817, USA 
Fig. 1 Outcome group probability (and SE) of failing response to name task by visit age

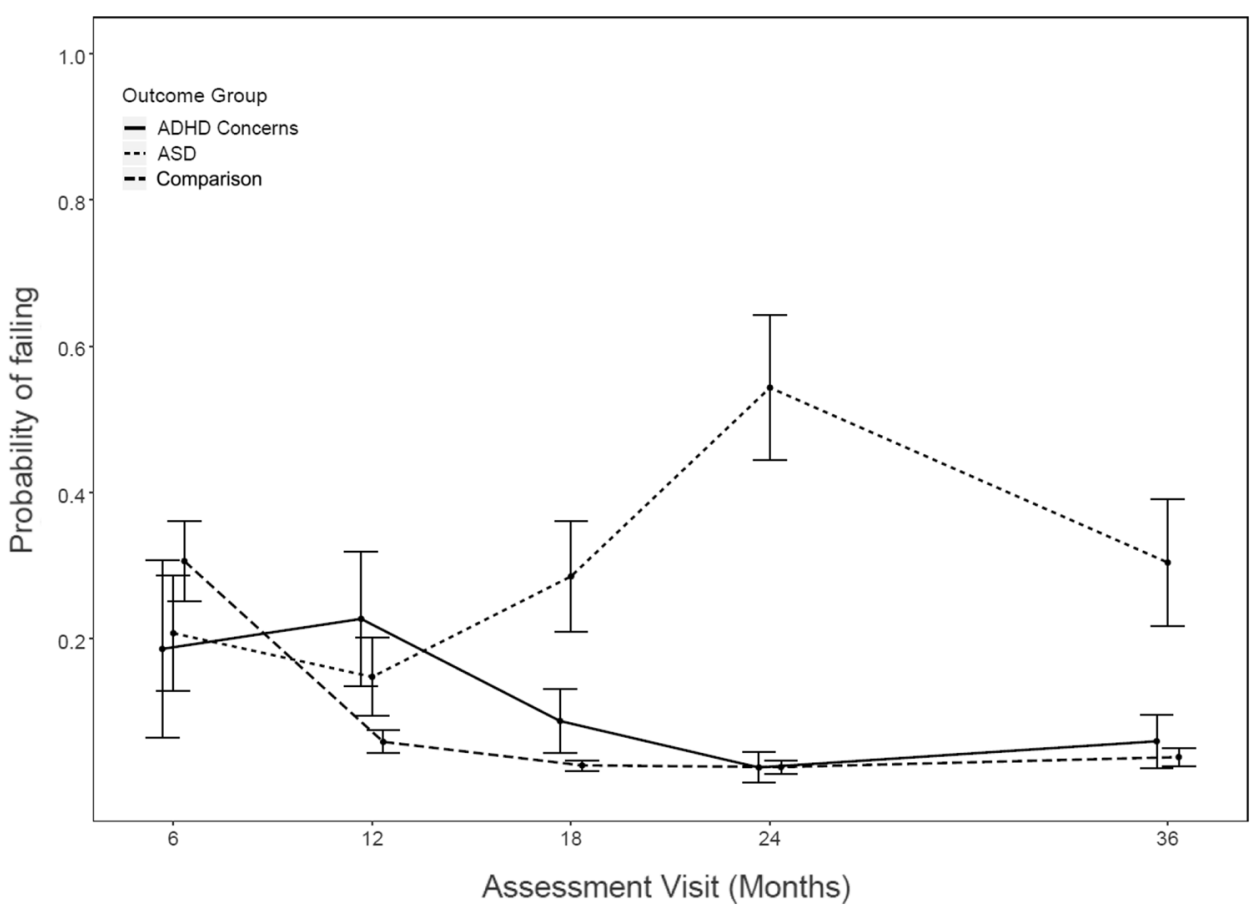

Publisher's Note Springer Nature remains neutral with regard to jurisdictional claims in published maps and institutional affiliations. 